\title{
Individual emergency physician admission rates: predictably unpredictable
}

\author{
David Mutrie, MA, MD; ${ }^{* \dagger}$ S. Kathleen Bailey, HBA; $;^{\dagger}$ Saleem Malik, PhD, MD ${ }^{* \dagger}$
}

\begin{abstract}
Objective: We sought to determine the degree and possible causes of variability in admission practices among individual emergency physicians (EPs) at 1 emergency department (ED) using a Canadian Emergency Department Triage Acuity Scale (CTAS)-matched ED patient population. Methods: We distributed a survey measuring attitudes and demographics to all EPs $(n=30)$ at a large regional hospital. Hospital admissions data from 1 calendar year were matched to individual EP survey results. Emergency physicians were ranked as "lower," "average" or "higher" admitters and, using these categorical variables, the data set was analyzed for correlations and trends.

Results: Overall, $97.0 \%$ of the EPs responded to the survey. Admissions by EPs ranged from $8.7 \%$ to $17.0 \%$, (mean 12.52, standard deviation [SD] 2.21) of all patients seen. CTAS category-specific admission data demonstrated variability in the admission ranking of individual EPs. No EPs consistently performed at any 1 admission ranking across all CTAS categories. More years of emergency medicine experience was significantly correlated with higher admissions in the CTAS-2 ranking $(r=$ $0.4, p<0.05)$. Whether a physician worked full-time, part-time or as a locum was not associated with patterns of admission, nor was any particular postgraduate certification (e.g., CCFP, CCFP EM, FRCPC) or any of the surveyed attitudinal traits.

Conclusion: Individual EPs' overall and CTAS-specific admissions varied substantially, and followed an approximately normal distribution curve. Emergency physicians with more years of experience had a statistically higher CTAS-2 admission rate; however, other variables, including postgraduate certification status, decision-related attitudes toward admission, and reported practices were not associated with admission proportions. Emergency physicians tend to have uniquely individual admission ranking profiles across all the CTAS categories.
\end{abstract}

Keywords: emergency physician admission rates

\section{RÉSUMÉ}

Objectif : Nous avons cherché à déterminer le degré de variabilité des taux d'hospitalisation et les causes possibles de cette variabilité parmi les médecins d'urgence d'un service d'urgence en analysant les données d'une population de patients classée selon les niveaux de l'Échelle canadienne de triage et de gravité pour les départements d'urgence (ÉTG).

Méthodes : Nous avons distribué un questionnaire pour mesurer les attitudes et les données démographiques de tous les médecins d'urgence $(n=30)$ dans un grand hôpital régional. Les données sur les admissions à l'hôpital d'une année civile ont été appariées aux résultats individuels des questionnaires remplis par les médecins d'urgence. Les pratiques des médecins quant à l'admission

From the *Thunder Bay Regional Health Sciences Centre, Thunder Bay, Ont., and the +Northern Ontario School of Medicine, Thunder Bay, Ont.

Submitted Jun. 19, 2008; Revised Oct. 10, 2008; Accepted Nov. 11, 2008

This article has been peer reviewed.

CJEM 2009;11(2):149-55 
ont été classées comme étant "faibles ", " moyennes " ou " supérieures ". On a analysé les données pour déterminer les corrélations et les tendances en fonction de ces variables.

Résultats : Dans l'ensemble, 97,0\% des médecins d'urgence ont répondu au questionnaire. Les taux d'admission variaient de 8,7 à $17,0 \%$ (médiane 12,52, écart-type 2,21) pour tous les patients vus à l'urgence. Les données sur les admissions classées selon les niveaux de l'ÉTG ont montré une variabilité des taux d'admission d'un médecin à l'autre. Aucun médecin d'urgence n'avait le même taux pour tous les niveaux de l'ÉTG. Ceux qui cumulaient plus d'années d'expérience en médecine d'urgence avaient un taux d'admission significativement plus élevé pour le niveau II de l'ÉTG $(r=0,4, p<$ $0,05)$. Aucune association n'a été établie entre les profils d'hospitalisation et le mode de travail du médecin (temps plein, temps partiel ou suppléance), la détention de diplômes postdoctoraux (p. ex., CCMF, CCMF(MU), FRCPC) ou les attitudes des médecins sondés relativement à l'hospitalisation.

Conclusion : Les taux d'admission en général et les taux d'admission en fonction du niveau de triage de l'ÉTG parmi les médecins individuels variaient sensiblement et présentaient une courbe de distribution quasi-normale. Les médecins d'urgence ayant plus d'années d'expérience affichaient un taux d'admission plus élevé pour le niveau II de l'ÉTG. Cependant, il n'y avait pas de corrélation entre les taux d'admission et les autres variables, y compris la certification, les attitudes liées à I'hospitalisation et les pratiques signalées. Les médecins d'urgence ont tendance à avoir leurs propres profils de classement aux fins d'admission pour tous les niveaux de l'ÉTG.

\section{Introduction}

The daily challenges faced by many urban Canadian emergency departments (EDs) that are forced to deal with a backlog of admitted patients have been outlined in detail. ${ }^{1-3}$ Many recommendations have been generated detailing how to address this problem by both national ${ }^{4,5}$ and provincial $^{6,7}$ task forces. Although there has been significant literature generated regarding "big picture" strategies to potentially impact actual collective ED admissions through the use of clinical decision units, and the implementation of systemic care plans and admission protocols, there is virtually no literature regarding the variability of admission practices among individual emergency physicians (EPs) and the potential role this variability may play in influencing the ED admission back$\log$. The failure to document and analyze the role of ED physicians in potentially exacerbating this known problem would appear to represent a glaring deficiency of professional accountability.

We tested the hypothesis that there is substantive variability among EPs in overall admitting practices and in Canadian Emergency Department Triage and Acuity Scale (CTAS)-matched admitting practices. Moreover, we sought to determine whether there were individual EP demographic or practice-related beliefs and attitudes associated with admission patterns. Outlined in this article are the results of a focused analysis of 1 year of CTASmatched admission data from a large urban community hospital (annual ED census approximately 88000 patients) and the results of our survey of the EPs practising at that facility. We analyzed whether admission rate variability among individual EPs correlated significantly with the EPs' demographic characteristics or with their attitudes regarding the extent to which selected factors contribute to the decision to admit a patient to hospital.

\section{Methods}

\section{Setting}

The study hospital is a Canadian 375-bed acute care institution that serves as a regional trauma and referral centre for a population of 250000 . This facility has the only ED within a $100-\mathrm{km}$ radius and provides on-site coverage 24 hours per day, 7 days per week. Emergency physician staffing is provided under an alternate funding arrangement using a set hourly rate.

\section{Admission process}

For the ED patient admission process during the study period (2006), the EP provided an initial assessment and investigation of all ED patients and then decided whether the patients should be discharged or if they required further inpatient care and investigation. If the EP felt hospital admission was necessary, he or she would then contact either the patient's admitting family physician (FP) or the on-call hospitalist (if the patient did not have an admitting FP) regarding the transfer of care. If the problem requiring admission was of a surgical nature then the appropriate oncall surgical consultant would be contacted regarding the transfer of care before admission. Typically, more than $85.0 \%$ of ED admissions were assessed by the attending physician (e.g., FP, hospitalist or surgical consultant) before admission from the ED to a hospital bed. 


\section{Physician survey}

We designed a questionnaire that consisted of a series of 5-point Likert-type scales, forced response and open-ended questions to elicit EPs' general demographic information, as well as their attitudes regarding the extent to which selected factors contribute to the decision to admit a patient to hospital. The surveyed admission-related factors were identified by a search of the relevant medical and psychological literature and included patient age, patient or family preference, availability of the specialist for consultation or FP for follow-up, specific versus general recall of similar case outcomes, bed availability, perception of peers or hospital administrators, time constraints and medicolegal considerations. The general demographic information for EPs included information on years of emergency medicine (EM) experience, postgraduate certification and clinical experience outside of the ED. To protect anonymity, physicians were not asked to identify sex because of the small number of women in the department. A convenience sample of 3 EPs piloted a draft questionnaire. Using feedback obtained in the pilot, we modified questions to ensure clarity and consensus regarding face validity. The 5-page questionnaire was hand delivered in June 2007 to all $(n=30)$ EPs working in the ED, with instructions for returning it on completion. We remained blinded to physician identity. All questionnaires were returned via a hospital administrative assistant, who labelled them with a 4-digit identifier before we received the material for coding and electronic data entry.

\section{Data collection}

The hospital's Information Systems Department provided an aggregated electronic data file for all visits to the ED from the 2006 calendar year, including CTAS score, whether a patient was admitted and the EP who wrote the admission-related transfer of care orders. The most responsible EP was identified with the same 4-digit system used to label the returned questionnaires. Overall admission proportions for individual EPs were calculated whereby the number of patients admitted by each EP was divided by the total number of ED patients who were treated by that physician. Individual CTAS categoryspecific admission rates were calculated whereby the number of patients with a specific CTAS score admitted by the EP was divided by the total number of patients with a specific CTAS score seen by that physician. Emergency physicians were ranked using standard deviations (SDs) from the mean to capture the upper and lower approximately $16.0 \%$ of physicians whose admission rates varied substantially from the mean of the group, both overall and within each CTAS category. We chose this arbitrary standard to capture only the most extreme scores in each CTAS category, rather than using interquartile ranges, which would have resulted in fewer physicians in the "average" category. Physicians whose admission rate was more than $1 \mathrm{SD}$ above or below the mean were labelled as "higher" or "lower," respectively. Those whose admission rates were within $1 \mathrm{SD}$ above or below the mean were labelled "average." Because of the small number of admitted patients in the CTAS- 5 category, this data set was removed from the analyses. Independent sample $t$ tests were conducted for all remaining CTAS-specific admission rate ranked groups to verify that physicians were properly grouped during data entry. Admission rate and ranking variables were added to the quantified questionnaire response set and analyzed for correlations using SPSS 15.0 for Windows (SPSS, Inc.). Analysis of variance (ANOVA) was performed to identify the relative contribution of employment and training on admissions.

\section{Ethics}

The hospital's Research Ethics Team determined that formal approval would not be required for a physician questionnaire with a retrospective database audit and the project was subsequently sanctioned at a regular meeting of EPs.

\section{Results}

\section{Emergency physician group}

Of the 30 surveys that were hand delivered, 29 (96.7\%) were completed and returned. Two physicians were excluded from the analysis: one, who was a new member of the ED, had completed the survey but saw no patients during the study period, and the other was assumed to be the only physician in the ED who restricted his or her parttime clinical ED practice to the exclusive provision of low-acuity "fast track" shifts. Identified as an outlier, this low-acuity physician had an abnormally low overall admission rate $(2.1 \%)$ and a completely different CTAS patient profile distribution compared with the other members of the group. All remaining EPs received an equitable distribution of the available ED shifts during the study period. The 27 physicians remaining in the study group (Table 1) were identified as the most responsible EP for $86.7 \%$ ( $n=76890)$ of all $2006 \mathrm{ED}$ visits with a mean patient volume of 3307 (range 404-4324, 95\% confidence interval [CI] 3297-3310). Because of the large size of our data set and the categorical nature of the survey data, we chose and carried out a 2-step cluster analysis in an attempt to define subgroups within the population based on 
survey responses, but revealed only one cluster in this very homogeneous group.

\section{Emergency department admission data}

The ED recorded 88691 patient visits during 2006, of which 11177 patients were admitted to hospital. Physicians' 2006 overall admission proportions (all CTAS categories pooled) varied from $8.7 \%$ to $17.0 \%$, with the data approximating a normal distribution (Fig. 1). This wide variability in admission rates was accurately predicted by $93.0 \%$ of survey respondents, who believed there would be a significant variation in the admitting rates of individual EPs. When asked how their individual admission rate compared with their colleagues, however, only 7 of 27 physicians accurately identified their true overall admission rate category (4 as average, 3 as lower than average). Eleven of the 27 physicians underestimated where they ranked in relation to their peers and only 3 of 27 overestimated their true admission rate ranking.

\section{CTAS subgrouping}

Admission variability was evident in all CTAS-specific categories (Fig. 2, Fig. 3, Fig. 4, Fig. 5). Many physicians showed within-subject, CTAS-specific variability, with their admitting practices fitting into multiple categories (higher, lower and average) across the 4 CTAS-specific categories. No physician fell exclusively within the higher,

\begin{tabular}{|c|c|}
\hline Characteristic & $\begin{array}{l}\text { No. (\%) of participants, } \\
\qquad n=27\end{array}$ \\
\hline \multicolumn{2}{|l|}{ Status } \\
\hline Full-time (13 shifts/mo) & $17(63.0)$ \\
\hline Part-time (6-12 shifts/mo) & $5(18.5)$ \\
\hline Less than part-time ( $<6$ shifts/mo) & $2 \quad(7.4)$ \\
\hline Locum & $3(11.1)$ \\
\hline \multicolumn{2}{|l|}{ EM experience, yr } \\
\hline$<3$ & $5(18.5)$ \\
\hline $3-10$ & $10(37.0)$ \\
\hline $10-20$ & $8(29.6)$ \\
\hline$>20$ & $4(14.8)$ \\
\hline \multicolumn{2}{|l|}{$\begin{array}{l}\text { EM always comprised majority of } \\
\text { practice }\end{array}$} \\
\hline Yes & $21(77.8)$ \\
\hline No & $6(22.2)$ \\
\hline \multicolumn{2}{|l|}{ Certifications } \\
\hline CCFP & $4(14.8)$ \\
\hline CCFP EM & $17(63.0)$ \\
\hline FRCPC & 2 (7.4) \\
\hline All of the above & 1 (13.7) \\
\hline None identified & $3(11.1)$ \\
\hline
\end{tabular}

lower or average admission rate ranking across all the CTAS-specific categories.

\section{Associations with survey data}

Using the Pearson correlation coefficient, physicians' years of EM experience was weakly and positively correlated with the higher CTAS-2 admission category $(r=0.4, p<$ $0.05)$. The correlation between years of EM experience and admission rates was negative, but did not reach statistical significance for all other CTAS categories. Whether physicians self-identified as working full-time (13 ED shifts/mo), part-time (6-12 ED shifts/mo), less than parttime $(<6 \mathrm{ED}$ shifts/mo) or as a locum did not predict a pattern of high or low rates of admission. No association was demonstrated between admission proportions and any particular postgraduate certification (i.e., CCFP, CCFP EM, FRCPC). Using a univariate ANOVA, there appeared to be a stronger effect from employment status $(F=0.59$, $p>0.5$, partial $\left.\mathrm{Eta}^{2}=0.10\right)$ than from training $(F=0.19$, $p>0.5$, partial $\mathrm{Eta}^{2}=0.04$ ) on overall admission category; however, the clinical relevance of this was unclear.

Survey responses showed that, based on self-report, various patient variables (i.e., age, sex, patient and family wishes, availability of FP for follow-up, patient history) and institutional variables (e.g., opinion of hospital administrators and colleagues, or bed availability) were given approximately equal weight across physicians when making the decision about whether to admit a patient. None of these variables alone or in combination were sufficient to predict EP admission ranking, either overall or CTAS-specific.

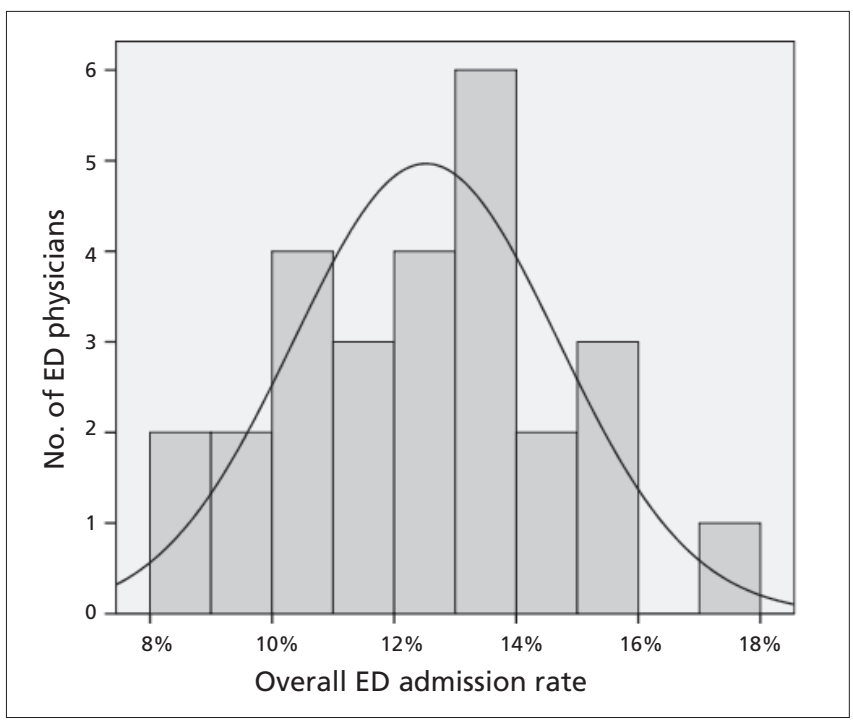

Fig. 1. Distribution of physician admission rates in 2006 (all Canadian Emergency Department Triage Acuity Scale categories). (Mean 12.52, 95\% confidence interval 11.66-13.39, standard deviation 2.17, $n=27$.) ED = emergency department. 


\section{Discussion}

To our knowledge, this is the first published Canadian study to identify individual EP admittance patterns of patients subgrouped by CTAS scores. The analysis of the ED admission data demonstrated that within the surveyed EP population, there was variation in both overall and CTAS category-specific individual physician admission decisions.

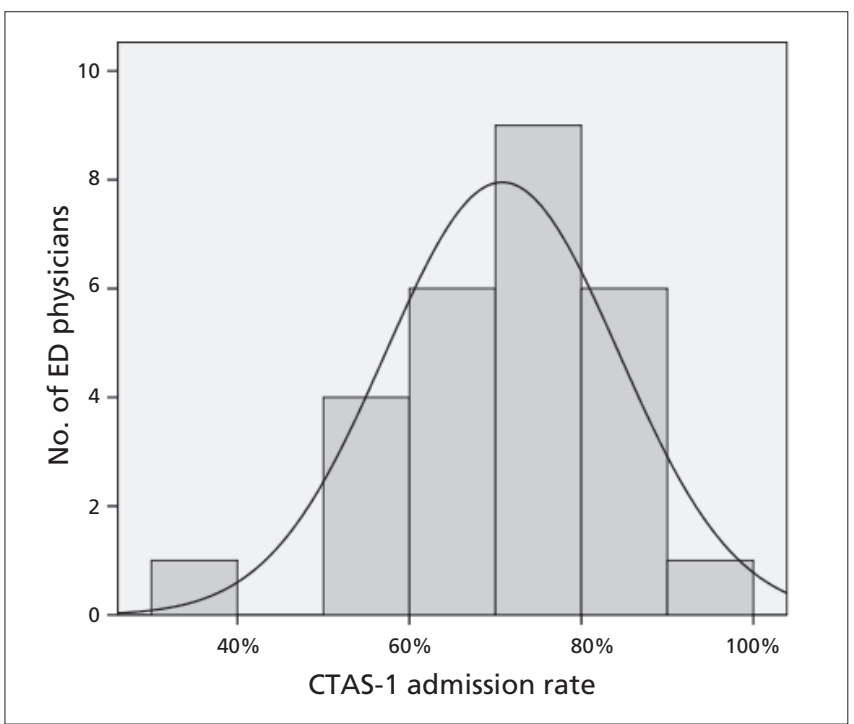

Fig. 2. Distribution of physician admission rates in 2006 (Canadian Emergency Department Triage Acuity Scale level 1 [CTAS-1]). (Mean 70.78, $95 \%$ confidence interval 65.43-76.14, standard deviation $13.54, n=27$.) $E D=$ emergency department.

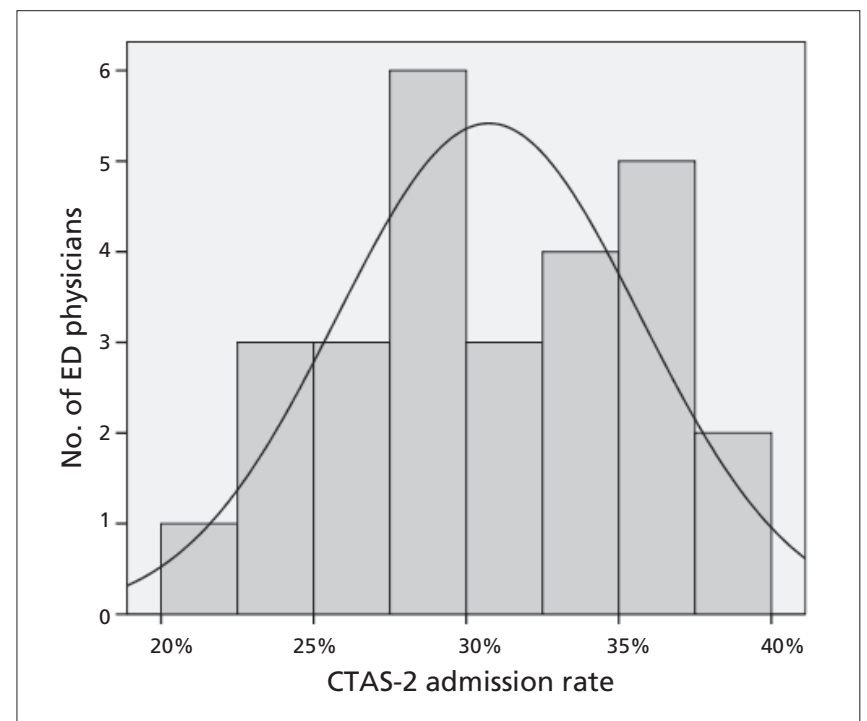

Fig. 3. Distribution of physician admission rates in 2006 (Canadian Emergency Department Triage Acuity Scale level 2 [CTAS-2]). (Mean 30.74, 95\% confidence interval 28.77-32.71, standard deviation $4.97, n=27$.) $E D=$ emergency department.
Examination of years of EM experience and postgraduate certification were not consistently associated with admission variability in this sample of EPs. These results also highlight the within- and between-physician variation in admissions.

Although this was a single-centred study, it is reassuring that the $12.5 \%$ overall proportion of ED admissions for this group of EPs is comparable to the national average of

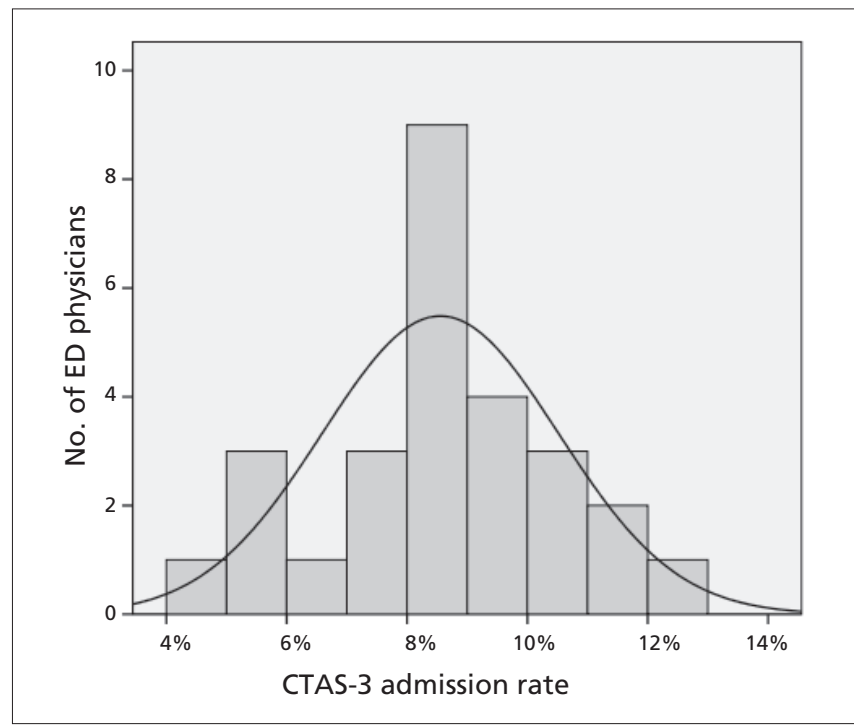

Fig. 4. Distribution of physician admission rates in 2006 (Canadian Emergency Department Triage Acuity Scale level 3 [CTAS-3]). (Mean 8.55, 95\% confidence interval 7.78-9.33, standard deviation 1.96, $n=27$.) $\mathrm{ED}=$ emergency department.

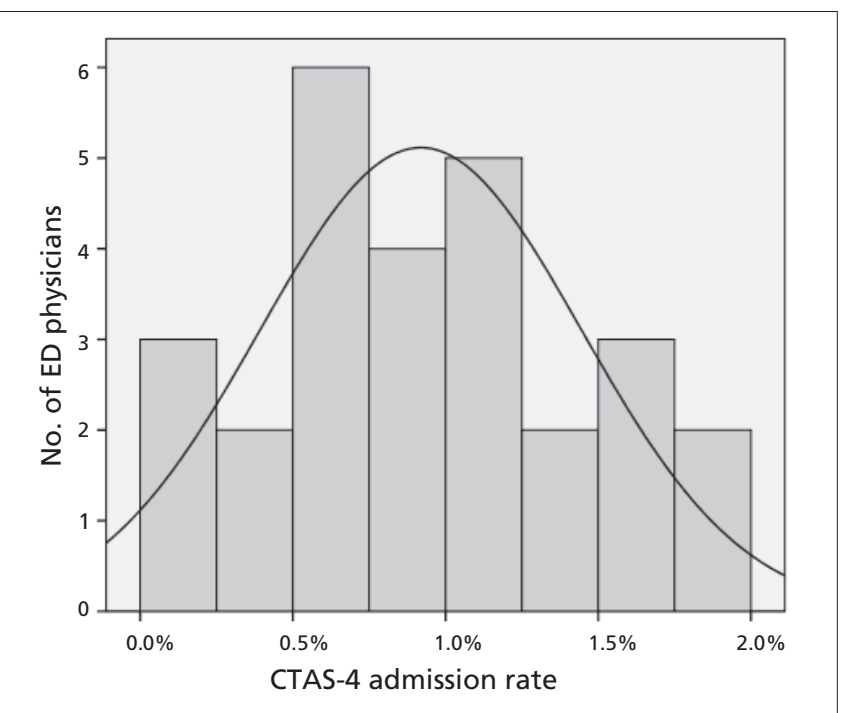

Fig. 5. Distribution of physician admission rates in 2006 (Canadian Emergency Department Triage Acuity Scale level 4 [CTAS-4]). (Mean 0.99, 95\% confidence interval $0.71-1.13$, standard deviation $1.53, n=27$.) $E D=$ emergency department. 
$12.6 \%$ (high-volume hospitals, $>30000$ annual visits), reported by Canadian Institute for Health Information in 2005. ${ }^{8}$ Moreover, the distribution of CTAS scores across this volume reflects similar data collected elsewhere. The study group's admission proportions (Table 2) were slightly below the provincial average (all hospital EDs regardless of size) for CTAS-2 through -5 patients, yet above the provincial average for CTAS- $1 .^{8}$ The relative congruity of the study data set points with these national and provincial benchmarks suggest that the generalizability of the results may be wider than originally anticipated.

Some important findings emerged from the survey. For example, $93.0 \%$ of the surveyed physicians believed there was a significant variance in individual EP admission rates, suggesting that variable individual ED admission rates are a readily accepted and acknowledged fact by the majority of practising EPs. In addition, with $73.0 \%$ of respondents underestimating (41.0\%), overestimating $(11.0 \%)$ or accurately estimating (21.0\%) their overall admission ranking, many EPs may be surprised to learn what their actual admission ranking is relative to their peers. Perhaps this "report card" function will be a future role to emerge from this type of research.

Efforts to explain the variability in admission decisions were largely unsuccessful. Although an isolated statistically significant trend of higher admissions was observed in physicians with more ED experience, the trend was limited to the CTAS-2 patient population. This trend mirrors the findings of Ting and colleagues, ${ }^{9}$ who found a predictable, incremental increase in cardiac admissions (accurate and false-positives) with more experience, in a group of newer physicians who triaged simulated cases. In the present study, the physicians with more ED experience demonstrated a trend to fewer admissions in all other CTAS categories; however, this trend failed to reach statistical significance. This observation warrants further study to determine whether the association between more ED experience and lower admissions in the non-CTAS-2 categories is valid. The prospect that ED experience is the

\section{Table 2. CTAS-specific rates of admission in Ontario (all} emergency departments) and study group

\begin{tabular}{lcc} 
& \multicolumn{2}{c}{ Rates of admission, \% } \\
\cline { 2 - 3 } CTAS level & Ontario* $^{*}$ & Study group \\
\hline 1 & 50.20 & 70.78 \\
2 & 35.90 & 30.74 \\
3 & 17.50 & 8.55 \\
4 & 3.20 & 0.99 \\
\hline \multicolumn{2}{c}{ CTAS = Canadian Emergency Department Triage Acuity Scale. } \\
*Source: National Ambulatory Care Reporting System.
\end{tabular}

most prominent predictor of admission patterns could potentially be of great benefit, as positive clinical experience may be amenable to strategic system resource improvement.

Our study failed to identify any consistent predictors of admission rate in association with a physician's postgraduate certification or surveyed attitudes related to the admission decision process, and this is consistent with the existing literature on the subject of physicians' practice patterns. Previous studies have demonstrated variable results predicting physicians' use of health care resources,${ }^{10}$ including guidelines, decision rules and care plans; ${ }^{11,12}$ and admitting practices ${ }^{13,14}$ using a variety of predictor variables. The outcomes of our analysis are largely consistent with Reilly and coworkers ${ }^{15}$ finding that physicians vary widely in their clinical decisions about simulated cases, regardless of specialty, level of training or clinical experience.

Of particular interest is our finding that the analysis of individual ED physician admission ranking demonstrated such wide between-subject and within-subject variability across all CTAS categories. From the data it was apparent that each EP demonstrated a unique admission profile made up of their overall admission ranking and their 4 CTAS category-specific rankings. The fact that there was such widespread CTAS category variance between physicians within any given overall ranking group may explain why it was so difficult to identify predictors of admission ranking. To clarify whether each physician's unique admitting profile can fit into a predictable model at all, further refinement in the admission data analysis may prove beneficial. The potential exists to develop CTAS-matched case mix group admission rates (i.e., all CTAS-3 abdominal pain), which could provide greater insight into individual EP admission practices that deviate substantively from their peers. It is likely that no simple fix is uniformly applicable to all ED physicians to address admission variability, but perhaps through timely and appropriate monitoring, targeted strategies can be developed to facilitate the more uniform application of ED admission thresholds.

We intend to use these data, in conjunction with additional data from 30-day patient follow-up, as a baseline measure for a pre- and poststudy of EPs' admission practice response to the implementation of an ED-driven admission strategy.

\section{Limitations}

There are several limitations to our study that need to be discussed. The use of a single study site and a correspondingly small EP sample raises the possibility that the observed results could be unduly influenced by admission 
characteristics, which may be site- or group-specific. No attempt was made to match CTAS scoring with presenting case mixed groups such as CTAS-2 chest pain or CTAS-3 abdominal pain. It was our belief, however, that a full year of patient visit data provided sufficient opportunity for an equitable distribution of CTAS and clinical scenarios among the physicians. In addition, because all the participating physicians were initially scheduled with an equitable distribution of shift types (i.e., midnights, weekends, evenings and days) no allowance was made for admission variations based on time of day or day of week factors. Individuals may have traded shifts to give an atypical shift distribution and accommodations were not made in our study to assess this potential confounder. CTAS scores provide a readily available and well-validated tool to allow researchers to compare patterns of care across hospitals, regions and provinces. CTAS scoring does involve some nurse discretion and this is another potential confounding variable that was not controlled in our study. We expect that the patient volume would be sufficient to distribute these variations equally among the physicians in our study. In addition, the very nature of survey research (i.e., reliance on self-reporting) is a limitation, albeit one that could not be avoided. Every observed score includes an element of error and survey research is especially susceptible. The response homogeneity observed in the survey could be indicative of impression management or some other form of reactivity rather than a true representation of the beliefs held by the physicians in this sample.

\section{Conclusion}

Notwithstanding the above limitations, the high survey response, the complete ED administrative data, the high patient volume of the ED and the acuity of the ED patients are strengths of our study. From the high degree of variability identified in the overall and CTAS-specific admission rates of individual ED physicians at this site, there would appear to be a considerable opportunity to develop initiatives to standardize admission profiles. Further analysis is warranted to match the rates of admission with longer term patient clinical outcomes to identify whether the high or low admitters are indeed admitting too many or too few patients.

Since more Canadian hospitals now collect and store ED data electronically, more in-depth analysis of ED admission practice patterns is now possible. In the future, researchers should attempt to replicate these findings in a larger sample of physicians while continuing to search for valid contributing factors and predictors of admission rate variability.
Competing interests: None declared.

\section{References}

1. Schull MJ, Slaughter PM, Redelmeier DA. Urban emergency department overcrowding: defining the problem and eliminating misconceptions. CJEM 2002;4:76-83.

2. Asplin BR, Magid DJ, Rhodes KV, et al. A conceptual model of emergency department crowding. Ann Emerg Med 2003;42: 173-80.

3. Estey A, Ness K, Saunders LD, et al. Understanding the causes of overcrowding in emergency departments in the Capital Health Region in Alberta: a focus group study. CJEM 2003;5: 87-94.

4. Canadian Association of Emergency Physicians. Taking action on the issue of overcrowding in Canada's emergency departments. Ottawa $(\mathrm{ON})$ : The Association; 2005. Available: www .waittimealliance.ca/waittimes/CAEP.pdf (accessed 2009 Jan 26).

5. Canadian Association of Emergency Physicians and the National Emergency Nurses Affiliation. Joint Position Statement. Access to acute care in the setting of emergency department overcrowding [policy]. CJEM 2003;5:81-6.

6. Physician Hospital Care Committee. Improving access to emergency care: addressing system issues, August 2006, Report of the Physician Hospital Care Committee. Toronto (ON): Ontario Hospital Association, Ontario Medical Association, Ontario Ministry of Health and Long-Term Care; 2006.

7. Drummond AJ. No room at the inn: overcrowding in Ontario's emergency departments. CJEM 2002;4:91-7.

8. Canadian Institute for Health Information. Understanding emergency department wait times. Who is using emergency departments and how long are they waiting? Toronto (ON): The Institute; 2005. Available: http://secure.cihi.ca/cihiweb/products /Wait_times_e.pdf. (accessed 2009 Jan 26).

9. Ting HH, Lee TH, Soukup JR, et al. Impact of physician experience on triage of emergency room patients with acute chest pain at three teaching hospitals. Am J Med 1991;91:401-8.

10. Donohoe MT, Kravitz RL, Wheeler DB, et al. Reasons for outpatient referral from generalists to specialists. J Gen Intern Med 1999;14:281-6.

11. Davis DA, Taylor-Vaisey A. Translating guidelines into practice: a systematic review of theoretic concepts, practical experience and research evidence in the adoption of clinical practice guidelines. CMAJ 1997;157:408-16.

12. Ellrodt AG, Conner L, Riedinger M, et al. Measuring and improving physician compliance with clinical practice guidelines: a controlled interventional trial. Ann Intern Med 1995;122:277-82.

13. Pearson SD, Goldman L, Orav EJ, et al. Triage decisions for emergency department patients with chest pain: Do physician's risk attitudes make the difference? J Gen Intern Med 1995;10: 557-64.

14. Nightingale SD. Risk preference and admitting rates of emergency room physicians. Med Care 1988;26:84-7.

15. Reilly BM, Evans AT, Schaider JJ, et al. Triage of patients with chest pain in the emergency department: a comparative study of physicians' decisions. Am J Med 2002;112:95-103.

Correspondence to: Dr. David Mutrie, 980 Oliver Rd., Thunder Bay ON P7B 6V4; dmutrie@tbaytel.net 